\title{
Carrier Detection of Partial Hypoxanthine-Guanine Phosphoribosyltransferase Deficiency by Analysis with BamHI Restriction Fragment Length Polymorphisms and Oligonucleotide Probes
}

\author{
TAKASHI IGARASHI AND SHIGEHIKO KAMOSHITA \\ Department of Pediatrics, Faculty of Medicine, The University of Tokyo, Tokyo 113, Japan
}

\begin{abstract}
Hyperuricemic nephropathy can progress to the permanent renal damage even in infancy in partial hypoxanthine-guanine phosphoribosyltransferase (HPRT) deficiency. We have encountered two unrelated patients with partial HPRT deficiency, and found that early detection of the disease and long-term management for hyperuricemia were necessary to prevent renal impairment. The HPRT gene is situated in the q26-27 region of the long arm of the $\mathrm{X}$-chromosome, and females with mutant HPRT alleles are heterozygous for the disease, and they develop gout after menopause. We undertook the investigation of carriers in the two patients' families, using BamHI restriction fragment length polymorphisms and oligonucleotide probes that recognized the specific mutations within the HPRT gene. We also demonstrated that the allele frequencies of BamHI restriction fragment length polymorphisms in 62 Japanese females were 0.36 for the $22-\mathrm{kb} / 25-\mathrm{kb}$ allele, 0.41 for the $12-\mathrm{kb} / 25-\mathrm{kb}$ allele, and 0.23 for the 22 $\mathrm{kb} / \mathbf{1 8}-\mathrm{kb}$ allele, resulting in a heterozygous state in $66 \%$ of females. (Pediatr Res 27: 417-421, 1990)
\end{abstract}

\section{Abbreviations}

HPRT, hypoxanthine-guanine phosphoribosyltransferase RFLP, restriction fragment length polymorphisms LN, Lesch-Nyhan

Deficiency of the enzyme HPRT (E.C.2.4.2.8) is associated with two clinical syndromes $(1,2)$. Complete absence of enzyme activity is responsible for $\mathrm{LN}$ syndrome, which is characterized by hyperuricemia, choreoathetosis, muscle spasticity, mental retardation, and compulsive self-mutilation (3). Patients with a partial deficiency of the enzyme activity are spared the devastating neurologic and behavioral abnormalities of $\mathrm{LN}$ syndrome (4). However, they present with hyperuricemia and a severe form of gout at an early age (5). Several recent reports have indicated that patients with partial HPRT deficiency or suspected LN syndrome can develop acute renal failure due to uric acid nephropathy in early infancy (6-8). Therefore, evaluation of the serum level of uric acid is necessary in male babies born to mothers who are the carriers of partial HPRT deficiency. If the male infant has hyperuricemia, fluid supplements and administration

Received August 29, 1989; accepted November 28, 1989

Correspondence: Dr. T. Igarashi, Department of Pediatrics, Faculty of Medicine, The University of Tokyo, 7-3-1 Hongo, Bunkyo-ku, Tokyo 113, Japan.

Supported by Grant-in-Aid for Scientific Research on Priority Areas, Ministry of Education, Science and Culture of Japan. of allopurinol are necessary to prevent neonatal acute uric acid nephropathy. Carrier women have an overproduction of uric acid throughout their lives. After menopause, the endogenous production of uricosuric estrogens declines, and the serum uric acid level increases resulting in gout (9). Thus, a reliable method to detect the carrier state is needed to help both these patients groups.

HPRT enzyme assay in erythrocytes or lymphoblasts is not able to discriminate the carrier state from normal, as erythrocytes or lymphoblasts from carrier women often show normal HPRT enzyme activity (10). Carrier state detection in LN syndrome has been performed by the demonstration of mosaicism for $\mathrm{HPRT}^{+}$ and HPRT $^{-}$clones of fibroblasts or lymphocytes and by the demonstration of two populations of hair roots, those with normal and those with either zero or subnormal levels of HPRT activity (11-16). The use of cells from hair follicles imposes logistical problems, and there is also evidence that each hair follicle is not truly clonal but is derived from two or three different cells $(13,17)$. Furthermore, both of these methods are time-consuming and although carriers can be identified, it is difficult to be sure that a negative result is absolutely reliable. These methods have not yet been applied to detecting the carrier state of partial HPRT deficiency. The clones derived from 8azaguanine- or 3-thioguanine-resistant cells from LN syndrome heterozygotes had the phenotype of HPRT-deficient cells since they did not incorporate hypoxanthine and had almost no HPRT activity. However, it was often impossible to demonstrate mosaicism with respect to $\mathrm{HPRT}^{+}$and partial $\mathrm{HPRT}^{+}$clones in partial HPRT deficiency; the partial HPRT ${ }^{+}$clone was often not resistant to either 8-azaguanine or 3-thio-guanine. Gibbs et al. (18) recently demonstrated the usefulness of BamHI RFLP in diagnosis of the carriage of LN syndrome. Twenty of 28 women, whose carrier state could not be determined by pedigree analysis or who were apparently normal according to the biochemical tests, were diagnosed as definite carriers on the basis of the RFLP analysis.

We have recently shown molecular abnormalities in two unrelated patients with partial HPRT deficiency. 1) Two singlebase substitutions were detected at codon 179 (from GTT to GGT) and codon 180 (from GGA to AGA), resulting in the putative replacement of valine with glycine and glycine with arginine. 2) The deletion of 51 nucleotides between nucleotides 747 and 797 was also found, resulting in the formation of a shorter HPRT mRNA and a putative two amino acid-deleted HPRT protein (19). In this study, we applied both oligonucleotide hybridization techniques and BamHI RFLP analysis to identify carriers in two unrelated families with partial HPRT deficiency. 
Table 1. Hypoxanthine-guanine phosphoribosyltransferase activity in erythrocytes*

\begin{tabular}{cc}
\hline Subject & $\begin{array}{c}\text { HPRT activity } \\
\text { (nmol/mg protein/min) }\end{array}$ \\
\hline Controls & $1.94 \pm 0.24(11)$ \\
Family A & \\
I.1 & 1.86 \\
II.1 & 2.27 \\
II.2 & 1.98 \\
II.3 & 2.04 \\
III.1 & 0.01 \\
III.2 & 0.00 \\
Family B & \\
II.3 & \\
II.4 & 2.05 \\
III.1 & 1.97 \\
III.2 & 0.19 \\
III.3 & 2.24 \\
\hline
\end{tabular}

${ }^{*}$ Control activity is the mean $\pm 1 \mathrm{SD}$ for the number of individuals given in parentheses. Family member numbers are as in Figure 1.
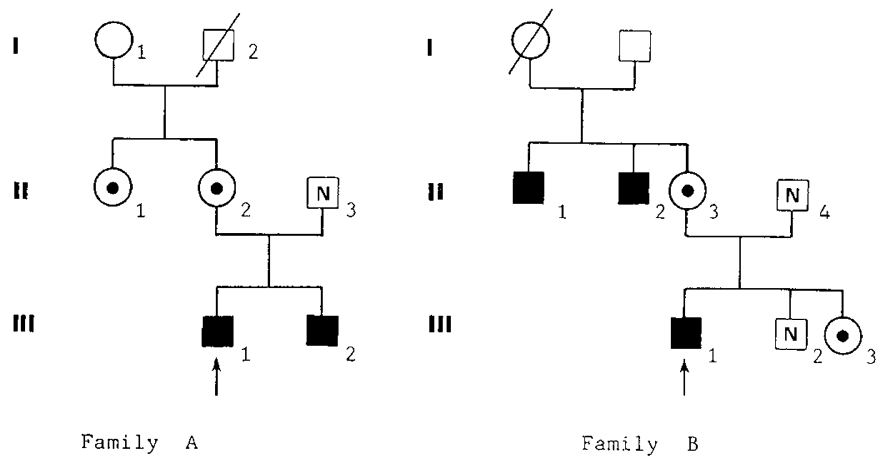

Fig. 1. Genealogic trees of two families affected with partial HPRT deficiency. Diagonal lines indicate dead family members. Dark boxes represent males affected with partial HPRT deficiency, circles with dots represent female carriers, and $N$ represents family members with normal erythrocyte HPRT enzyme activity. The propositus is identified by an arrow in each family.

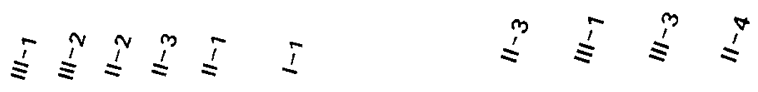

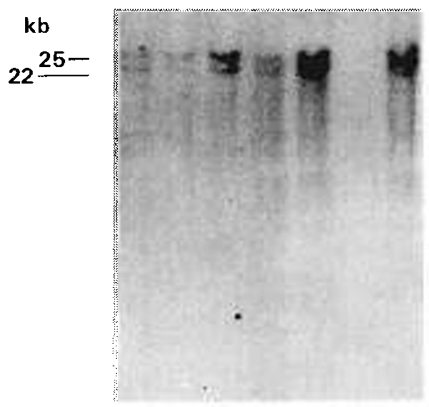

A

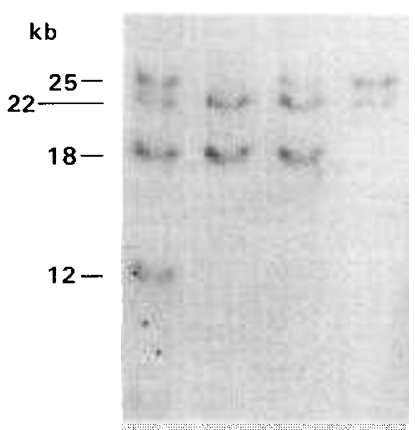

B
Fig. 2. Southern blot analysis of peripheral WBC HPRT DNA in two families A and B. Numbers on each track indicate the same family members as in Figure 1.

\section{MATERIALS AND METHODS}

Subjects. Nine subjects belonging to two families with partial HPRT deficiency were studied. In addition, 62 normal females were analyzed by Southern blotting to determine the average level of heterozygosity for BamHI RFLP.
A

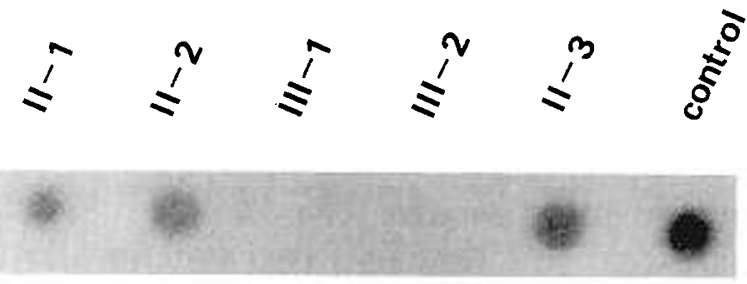

B

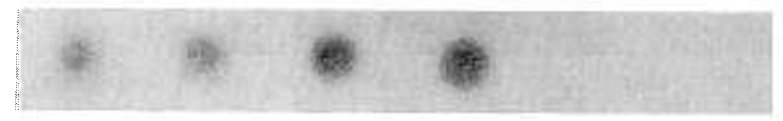

Fig. 3. Oligonucleotide hybridization analysis of genomic DNA from a normal individual, carriers, and patients in family A. $A$ and $B$ are autoradiographs of the membranes after hybridization with normal oligonucleotide probe $\mathrm{A}$ and mutant oligonucleotide probe $\mathrm{B}$, respectively. Numbers on each dot indicate members of family A as in Figure 1. Control represents a normal female.
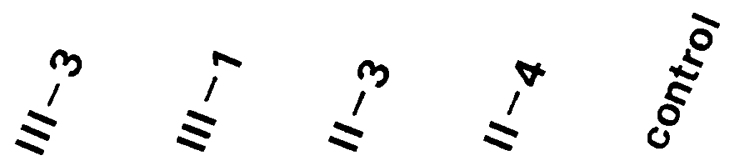

\section{C}

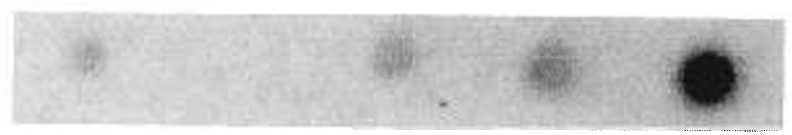

Fig. 4. Oligonucleotide hybridization analysis of genomic DNA from a normal individual, carriers, and the patient in family B. $C$ is an autoradiograph of the membrane after hybridization with normal oligonucleotide probe C. Numbers on each dot indicate the members of family $\mathrm{B}$ as Figure 1. Control represents a normal female.

Red cell lysates and enzyme assays. Red cell lysates were prepared from heparinized venous blood by centrifugation at 70 $\times g$ for 10 min followed by removal of plasma and the buffy coat. Red cells were washed four times for an equal volume of PBS at $4^{\circ} \mathrm{C}$. Packed red cells were suspended in an equal volume of $10 \mathrm{mmol}$ phosphate $(\mathrm{pH} 7.3)$ and lysed by sonication. Lysates were centrifuged at $7000 \times g$ for $30 \mathrm{~min}$ and the supernatants were recovered for assay at $-70^{\circ} \mathrm{C}$.

Sensitive radiochemical techniques were used to quantify HPRT enzyme activity in $50 \mathrm{mmol}$ Tris- $\mathrm{HCl}(\mathrm{pH} 7.4)$ containing $5 \mathrm{mmol} \mathrm{HgCl}_{2}, 1 \mathrm{mmol}$ 5-phospho-D-ribose-1-pyrophosphate (Sigma Chemical Company, St. Louis, MO), $0.1 \mathrm{mmol}\left[{ }^{14} \mathrm{C}\right]-$ hypoxanthine (sp act $50-55 \mathrm{mCi} / \mathrm{mmol}$ ), and $1.5 / 2.5 \mathrm{mg} / \mathrm{mL}$ protein. Incubation was performed for $10-15 \mathrm{~min}$ at $37^{\circ} \mathrm{C}(20)$.

DNA isolation and Southern blot analysis. High mol wt DNA was isolated from peripheral blood samples as described in the literature (21). DNA samples of $7.5 \mu \mathrm{g}$ were digested to completion with restriction endonuclease BamHI (Boehringer Mannheim $\mathrm{GmbH}$, Mannheim, FRG) at a concentration of $5 \mathrm{U} / \mu \mathrm{L}$, and fractionated in $0.8 \%$ agarose gels (Ultrapure agarose, Bethesda Research Laboratories, Gaithersburg, MD) treated according to the method of Whal et al. (22). Samples were then transferred into nitrocellulose filters and hybridized with ${ }^{32} \mathrm{P}$ deoxycytidine triphosphate labeled full-length HPRT cDNA (pHP31; provided by Dr. W. N. Kelley) (sp act of more than $3000 \mathrm{Ci} / \mathrm{mmol}$, Amersham Japan, Tokyo, Japan). Probes were labeled to a sp act of $1-3 \times 10^{8} \mathrm{cpm} / \mu \mathrm{g}$ using a multiprime DNA labeling system (Amersham Japan). Hybridization was carried out at $42^{\circ} \mathrm{C}$ in a mixture containing $50 \%$ formamide. Hybridization patterns were visualized by autoradiography.

Oligonucleotide synthesis and dot-blot analysis of genomic 
Table 2. Survey of phenotypes and X chromosomes with BamHI RFLPs in unrelated Japanese females

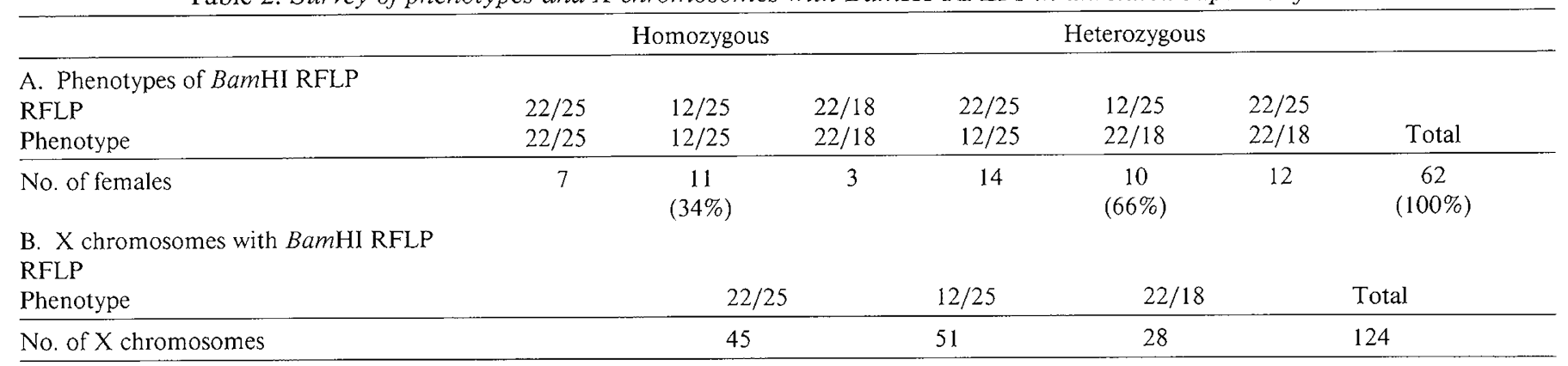

$D N A$. Three 18 mer oligonucleotide probes were synthesized. Probe A (5'-TTCAAATCCAACAAAGTC-3') was complementary to normal HPRT cDNA and ranged between nucleotides 628 and 645 [nucleotide numbers were those assigned by Jolly et al. (23)]. Mutant probe B(5'-TTCAAATCTACCAAAGTC$3^{\prime}$ ) was complementary to the putative mutant HPRT cDNA and ranged between nucleotides 628 and 645 from patient T.A. Probe C (5'-TCAACTTGAACTCTCATC-3') was complementary to normal HPRT cDNA and ranged between nucleotides 757 and 774 , the region that was considered to possibly be deleted from the HPRT cDNA of patient M.T. Genomic DNA samples of $20 \mu \mathrm{g}$ were applied directly by the dot-blot method onto nitrocellulose filters and analyzed by hybridization with oligonucleotide probes. Probes were labeled by ${ }^{32} \mathrm{P}$-adenosine triphosphate (sp act of more than $3000 \mathrm{Ci} / \mathrm{mmol}$, Amersham Japan) using T4 polynucleotide kinase (New England BioLabs). The hybridization temperature was specific to each probe, being $43^{\circ} \mathrm{C}$ for probe $\mathrm{A}, 41^{\circ} \mathrm{C}$ for probe $\mathrm{B}$, and $45^{\circ} \mathrm{C}$ for probe $\mathrm{C}(24)$. Hybridization patterns were visualized by autoradiography.

\section{CASE REPORTS}

Family A. T.A. was born without complications on 8/7/1977. The birth wt was $3100 \mathrm{~g}$. Both parents were healthy and there was no history of gout in either parent's family. Large amounts of orange colored crystals were seen in the diapers when the patient was 3 mo old. Hyperuricemia (serum uric acid $6.8 \mathrm{nmol} /$ L) was found, and administration of allopurinol was started by the local hospital. The erythrocyte HPRT activity was determined at Tokyo University Hospital. This was less than $0.7 \%$ of the normal value, and LN syndrome was suspected initially. With careful control, the serum uric acid level was kept less than $3.8 \mathrm{nmol} / \mathrm{L}$ and the renal function remained within normal limits. The patient showed normal development without any of the neurologic symptoms that are characteristic of LN syndrome. HPRT activity in B cell lymphoblasts was determined in 1979 to be $3.9 \%$ of the normal value. The low HPRT activity in his lymphoblasts, together with the clinical course, made the diagnosis partial HPRT deficiency. A brother was born normally on $9 / 21 / 1980$. He also showed hyperuricemia (serum uric acid 7.1 $\mathrm{nmol} / \mathrm{L}$ ) and negative erythrocyte HPRT activity (less than $0.7 \%$ of the normal value), and was started on allopurinol. Both of them are currently healthy, without any attacks of gout, urolithiasis, renal impairment, or neurologic symptoms.

Family B. M.T. was born healthy on $12 / 19 / 1972$. The mother's brothers had gout and were being treated with allopurinol. The patient had a urinary calculus in 1982, and several episodes of swelling of the right big toe joint in 1983 and 1984. He presented to Tokyo University Hospital in 1984. Hyperuricemia (serum uric acid $7.6 \mathrm{nmol} / \mathrm{L}$ ) was found, and administration of allopurinol was started. Radiographic examination demonstrated periarticular bone resorption in the joints of the big toes. The creatinine clearance was $48 \mathrm{~mL} / \mathrm{min} / 1.73 \mathrm{~m}^{2}$ and urinary $\beta-2$ microglobulin excretion was increased (4574 $\mu \mathrm{g} /$ day). The arte- rial concentration of $\mathrm{HCO}_{3}{ }^{-}$was $24 \mathrm{mmol} / \mathrm{L}$. The erythrocyte HPRT activity was $9.8 \%$ of the control level, and therefore partial HPRT deficiency was diagnosed. He did not have any of the neurologic symptoms that are seen in LN syndrome. With treatment, the serum uric acid level was kept less than $3.8 \mathrm{nmol} / \mathrm{L}$. However, the impairment of creatinine clearance and the hyper$\beta-2$ microglobulinuria ( $3470 \mu \mathrm{g} /$ day) persisted.

\section{RESULTS}

Erythrocyte HPRT enzyme activity (Table 1, Fig. 1). The erythrocyte HPRT enzyme activity levels are summarized in Table 1. HPRT enzyme activity was undetectable in erythrocytes (less than $0.7 \%$ of the control) from patients III. 1 and III.2 of family A. It was decreased to $9.8 \%$ of the control level in patient III. 1 from family B. Carrier mothers II. 2 from family A and II. 3 from family B showed normal HPRT activity. Members II.1 from family A (the sister of carrier mother) and III. 3 from family $\mathrm{B}$ (the daughter of carrier mother) also showed normal HPRT activity.

Southern blot analysis of the HPRT gene (Fig. 2). BamHII RFLP were expressed phenotypically on Southern blots as three distinct pairs of fragments in normal Caucasian and Japanese population: a 22-kb/25-kb pair (frequency in the Caucasian population 0.77$)$; a $12-\mathrm{kb} / 25-\mathrm{kb}$ pair $(0.16)$; and a $22-\mathrm{kb} / 18-\mathrm{kb}$ pair (0.07) (25).

In family $\mathrm{A}$, members III.1 (the propositus) and III.2 (his brother) had the $22-\mathrm{kb} / 25-\mathrm{kb}$ allele, and members $\mathrm{I} .1$ (his grandmother, a suspected carrier), II.2 (the carrier mother) and II.1 (the sister) also showed the double $22-\mathrm{kb} / 25-\mathrm{kb}$ pattern. Therefore, it was not possible to identify which of their X chromosomes carried the mutant gene, the BamHI polymorphism analysis was not helpful.

In family B, member III. 1 (the propositus) had the $22-\mathrm{kb} / 18$ $\mathrm{kb}$ allele that therefore marked the X-chromosome carrying the mutant HPRT gene. Member II.4, the father of the propositus, had the $22-\mathrm{kb} / 25-\mathrm{kb}$ allele, whereas member II.-3 (the carrier mother) showed the combination of a $22-\mathrm{kb} / 18-\mathrm{kb}$ allele and a $12-\mathrm{kb} / 25-\mathrm{kb}$ allele. Member III.3, the sister of the propositus, had the combination of $22-\mathrm{kb} / 25-\mathrm{kb}$ and $22-\mathrm{kb} / 18-\mathrm{kb}$, and she was thus considered to be a carrier. The BamHI polymorphism analysis was therefore quite informative in this family.

Dot-blot analysis with oligonucleotide probes (Figs. 3 and 4). Genomic DNA from family members II.1 (the sister of the carrier mother), II.2 (the carrier mother), and II.3 (the father) of family $A$ and a family control hybridized to normal probe $A$, which was complementary to normal HPRT CDNA ranging between nucleotides 628 and 645 . The control dot appeared to be twice the intensity of the dots from members II. 2 and II.3 However, genomic DNA from family members III.1 (the propositus) and III. 2 did not hybridize to the probe A. However, genomic DNA from members II.1, II.2, III.1, and III. 2 of family A hybridized to the mutant probe $B$, which was complementary to a putative mutant HPRT CDNA ranging between nucleotides 628 and 645 
in the propositus. Genomic DNA from members II.3 and a female control did not hybridize to the probe $\mathrm{B}$. These results implied that member II. 1 was a carrier. Although BamHI RFLP analysis had not been informative in this family, analysis with patient-specific and normal oligonucleotide probes was able to diagnose a carrier.

Genomic DNA from members II.3 (the carrier mother), II.4 (the father), and III.3 (the daughter) in family B hybridized to the probe $\mathrm{C}$, which was complementary to normal HPRT cDNA ranging between nucleotides 757 and 774 . Genomic DNA from member III.1 (the propositus) did not hybridize to probe $C$, because the region complementary to the probe was included in the 51 nucleotide deletion in the HPRT gene of the patient. The dot intensity of the carrier mother was almost equal to that of the daughter (III.3), and the intensity of the dot from the control female was almost twice as strong implying that III.3 was a carrier. This agreed with the result of the BamHI RFLP analysis.

Population study (Table 2). A survey of the BamHI RFLP phenotypes from 62 unrelated Japanese females is summarized in Table 2. Overall, $36 \%$ of X chromosomes carried the $22-\mathrm{kb} /$ $25-\mathrm{kb}$ allele, $41 \%$ carried the $12-\mathrm{kb} / 25-\mathrm{kb}$ allele, and $23 \%$ had the $22-\mathrm{kb} / 18-\mathrm{kb}$ allele. Given these allele frequencies, $66 \%$ of Japanese females were heterozygous with respect to $\mathrm{Bam} \mathrm{HI}$ RFLP.

\section{DISCUSSION}

Hyperuricemia is known to cause hyperuricemic nephropathy in which deposition of uric acid crystals in the tubules leads to rupture of the tubular basement membrane and thus to more severe interstitial and glomerular involvement. Recurrent episodes of nephropathy, either symptomatic or nonsymptomatic, can progress to permanent renal impairment (26). We encountered two patients with partial HPRT deficiency, and found that early detection of the disease and long-term management of hyperuricemia is mandatory to prevent renal impairment in this disease.

BamHI RFLP analysis was informative to detect carriers of partial HPRT deficiency in family B, but was not helpful in family A. An additional TaqI RFLP, which has been reported for an anonymous sequence (DXS-10) closely linked to HPRT locus, can be applied to detect carriers in family A (27).

Hybridization analysis of amplified or unamplified genomic DNA with mutant oligonucleotide probes is also known to be feasible for carrier detection $(28,29)$. When BamHI RFLP analysis was noninformative, genotypes could still be partially distinguished by direct analysis of mutation sites within the HPRT gene. Dot blot analysis with normal and mutant oligonucleotide probes clearly separated the normal members, the carrier, and the patient in family A. Moreover, dot-blot analysis with normal oligonucleotide probe confirmed the result shown by BamHI RFLP analysis in family $\mathrm{B}$.

For determination of carrier status in the at-risk daughter of a carrier mother using BamHI RFLP analysis, it is necessary to identify which chromosome carries the HPRT mutant gene in the mother. Thus, she must be heterozygous with respect to the BamHI RFLP phenotype. Nussbaum et al. (25) surveyed 83 independent $X$ chromosomes from 30 families for Bam HI RFLP, and reported that the allele frequencies in the Caucasian population were 0.77 for the $22-\mathrm{kb} / 25-\mathrm{kb}$ allele, 0.16 for the 12 $\mathrm{kb} / 25-\mathrm{kb}$ allele, and 0.07 for the $22-\mathrm{kb} / 18-\mathrm{kb}$ allele, resulting in an average heterozygosity of $38 \%$ in females. However, our study showed that the allele frequencies in the Japanese female population were 0.36 for the $22-\mathrm{kb} / 25-\mathrm{kb}$ allele, 0.41 for the $12-\mathrm{kb} /$ $25-\mathrm{kb}$ allele, and 0.23 for the $22-\mathrm{kb} / 18-\mathrm{kb}$ allele, indicating that $66 \%$ of Japanese females were heterozygous for BamHI RFLP, a higher rate than in Caucasian females. In this respect, we cannot exclude the possibility that racial factors contributed to the different results of the two studies. No difference has been found between the frequencies of the BamHI RFLP in normal
$\mathrm{X}$ chromosomes, $\mathrm{X}$ chromosomes bearing HPRT mutations, and $\mathrm{X}$ chromosomes in individuals with a variety of $\mathrm{X}$-linked diseases (25).

Accordingly, BamHI RFLP analysis could be applied to the families with the disease more effectively in Japan than in countries with a predominantly Caucasian population.

\section{REFERENCES}

1. Lesch M, Nyhan WL 1964 A familial disorder of uric acid metabolism and central nervous system function. Am J Med 36:561-570

2. Seegmiller JE, Rosenbloom FM 1967 Enzyme defect associated with a sexlinked human neurological disorder and excessive purine synthesis. Science 155:1682-1684

3. Mizuno T 1986 Long-term follow-up of ten patients with Lesch-Nyhan syndrome. Neuropediatrics 17:159-161

4. Kelly WN, Greene ML, Rosenbloom FM, Henderson JF, Seegmiller JE 1969 Hypoxanthine-guanine phosphoribosyltransferase deficiency in gout. Ann Intern Med 70:155-206

5. Lorentz WB, Burton BK, Trillo A, Browning MC 1984 Failure to thrive, hyperuricemia, and renal insufficiency in early infancy secondary to partial hypoxanthine-guanine phosphoribosyltransferase deficiency. $\mathrm{J}$ Pediatr 104:94-97

6. Wingen AM 1985 Acute renal failure in an infant with partial deficiency of hypoxanthine-guanine phosphoribosyltransferase. Proc EDTA-ERA 21:751755

7. Andres A, Praga M, Ruilope LM 1987 Partial deficit of hypoxanthine-guanine phosphoribosyltransferase presenting as acute renal failure. Nephron 46:179181

8. Holland PC, Dillon MJ, Pincott J, Simmonds HA, Barratt TM 1983 Hypoxanthine-guanine phosphoribosyltransferase deficiency presenting with gout and renal failure in infancy. Arch Dis Child 58:831-833

9. Wilson JM, Young AB, Kelley W 1983 Hypoxanthine-guanine phosphoribosyltransferase deficiency: the molecular basis of the clinical syndromes. $\mathrm{N}$ Engl J Med 309:900-910

10. DeMars R 1971 Genetic studies of HG-PRT deficiency and the Lesch-Nyhan syndrome with cultured human cells. Fed Proc 3:944-955

11. Frost P, Weinstein G, Nyhan WL 1970 Diagnosis of Lesch-Nyhan syndrome by direct study of skin specimens. JAMA 212:316-319

12. Felix JS 1971 Detection of female heterozygous for the Lesch-Nyhan mutation by 8 -azaguanine-resistant growth of cultured fibroblasts. J Lab Clin Med 77:596-604

13. Gartler SM, Scott RC, Goldstein JL, Campbell B, Sparkes R 1971 LeschNyhan syndrome: rapid detection of heterozygotes by use of hair follicles. Science 172:572-574

14. Silvers DN, Cox RP, Balis ME, Dancis J 1972 Detection of the heterozygote in Lesch-Nyhan disease by hair-root analysis. N Engl J Med 286:390-395

15. Francke U, Bakay B, Nyhan WL 1973 Detection of heterozygous carriers of the Lesch-Nyhan syndrome by electrophoresis of hair root lysates. J Pediatr 82:472-478

16. Dempsy JL, Morley AA, Seshadri RS, Emmerson BT, Gordon R, Bhagat CI 1983 Detection of the carrier state for an X-linked disorder, the LeschNyhan syndrome, by the use of lymphocyte cloning. Hum Genet 64:288290

17. Dancis J, Silvers DN. Balis ME, Cox RP, Schwartz MS 1981 Evidence for the derivation of individual hair roots from three progenitor cells. Hum Genet 58:414-416

18. Gibbs DA, Headhouse-Benson CM, Watts RWE 1986 Family studies of the Lesch-Nyhan syndrome: the use of a restriction fragment length polymorphism (RFLP) closely linked to the disease gene for carrier state and prenatal diagnosis. J Inherited Metab Dis 9:45-58

19. Igarashi T, Minami M, Nishida Y 1989 Molecular analysis of hypoxanthineguanine phosphoribosyltransferase mutations in five unrelated Japanese patients. Acta Paediatr Jpn 3:303-313

20. Snyder FF. Mendelsohn J, Seegmiller JE 1976 Adenosine metabolism in phytohemagglutinin-stimulated human lymphocytes. J Clin Invest 58:654666

21. Gross-Belland M, Oudet P, Chambon P 1973 Isolation of high-molecular weight DNA from mammalian cells. Eur J Biochem 36:32-38

22. Whal GM, Stem M, Stark GR 1979 Efficient transfer of large DNA fragments from agarose gels to diazobenzoloxymethal paper and rapid hybridization using dextran sulfate. Proc Natl Acad Sci USA 76:3683-3687

23. Jolly DJ, Okayama H, Berg P, Esty C, Filpula D, Bohlen P, Johnson GG, Shively JE, Hunkapillar T, Friedmann T 1983 Isolation and characterization of a full-length expressible cDNA for human hypoxanthine phosphoribosyltransferase. Proc Natl Acad Sci USA 80:477-481 
24. Zeff RA, Geliebten J 1987 Oligonucleotide probes for genomic DNA blots. Focus 9:1-2

25. Nussbaum RL, Crowder WE, Nyhan WL, Caskey T 1983 A three-allele restriction fragment-length polymorphism at the hypoxanthine phosphoribosyltransferase locus in man. Proc Natl Acad Sci USA 80:4035-4039

26. Emmerson BT, Row PG 1975 An evaluation of the pathogenesis of the gouty kidney. Kidney Int 8:65-71

27. Wilson JM, Stout JT, Palella TD, Davidson BL, Kelly WN, Caskey CT 1986
A molecular survey of hypoxanthine-guanine phosphoribosyl transferase deficiency in man. J Clin Invest 77:188-195

28. DiLella AG, Marvit J, Lidsky AS, Guttler F, Woo SLC 1986 The linkage between a splicing mutation and a specific DNA haplotype in phenylketonuria. Nature 322:799-803

29. DiLella AG, Huang W-N, Woo SLC 1988 Screening for phenylketonuria mutations by DNA amplification with the polymerase chain reaction. Lancet 1:497-499 